\title{
ANTIOXIDANT ACTIVITY OF SWIETENIA MACROPHYLLA KING BARK EXTRACTS
}

\author{
Masendra, Brandon Aristo Verick Purba, Ganis Lukmandaru \\ Universitas Gadjah Mada \\ INDONESIA
}

(Received March 2020)

\begin{abstract}
This study investigated the antioxidant activity from the methanol $(\mathrm{MeOH})$ soluble extract of the inner and outer bark of Swietenia macrophylla. The $\mathrm{MeOH}$ soluble extracts were fractionated into ethyl acetate (EtOAc) soluble and insoluble. The antioxidant activity was conducted by DPPH (1,1-diphenyl-2-picrylhydrazyl) method and the phenolic compounds were detected by GC-MS. The levels of total phenolic content of soluble and insoluble fraction of EtOAc of outer bark were higher than in inner bark, while total flavonoid content showed opposite results. The crude methanol extract and its EtOAc soluble fraction of outer bark showed a higher level of antioxidant activity. The GC-MS analysis detected higher levels of fatty acids and alcohols of $87.12 \%$ than phenolic compounds of $12.17 \%$ in the inner bark, while the outer bark showed the opposite pattern with phenolic compounds of $82.65 \%$ than fatty acids of $8.43 \%$. A strong correlation was demonstrated between total phenolic content and antioxidant activity.
\end{abstract}

KEYWORDS: Swietenia macrophylla, bark extractives, phenols, flavonoid, phytomedicines.

\section{INTRODUCTION}

Bark is the outermost part of a plant stem which acts as a protective layer against external forces such as wind, snow, and various disease-causing organisms. Anatomically, it consists of periderm in its outer part, and parenchyma on the inner part (Rosell et al. 2014). The outer and inner part of bark can be distinguished by its cells, function, and properties. The outer bark part of a tree, referred to botanically as the rhytidome, consists of dead tissues, fats, and suberins. Meanwhile, the inner part of bark mostly contains living cells and is referred to as the phloem. The inner bark also serves as storage for nutrients such as sugars and fatty acids (Morris et al. 2016, Masendra et al. 2018).

The protective functions of bark are often associated with bioactive compounds from secondary metabolites, mainly from tannins or polyphenols. The bioactivities shown by these compounds have been regarded as potential material for traditional medicine and for use by 
pharmaceutical industries (Ogawa and Yazaki 2018, Elansary et al. 2019). One well-known utilization of bark can be found in the standardized Pycnogenol ${ }^{\circledR}$ from the species of Pinus pinaster, which contains phenolics e.g. taxifolin, catechin, procyanidin, and phenolic acids and shows high antioxidant activity against reactive oxygen and nitrogen species (Iravani and Zolfaghari 2011).

Phenolic compounds have been referenced in many literatures for their ability to promote health and to prevent disease through their antioxidant, anti-inflammatory, anti-obesogenic, and other beneficial properties (Pérez-Jiménez et al. 2010, Singh et al. 2011, Wang et al. 2014, Cory et al. 2018). Eating foods that are rich in flavonoids has been shown to improve cardiovascular health and lower blood pressure (Rees et al. 2018). Furthermore, polyphenol type compounds have been known to act as an antioxidant, which is able to neutralize free radical compounds such as hydrogen peroxide $\left(\mathrm{H}_{2} \mathrm{O}_{2}\right)$ that can cause damage to cells (Halliwell and Gutteridge 1999, Sroka and Cisowski 2003). The effectively of polyphenols to neutralize free radicals is diverse and affected mainly by their structure. For example, previous research by Sroka and Cisowski (2003) on phenolic acids found stronger antioxidant activity with compounds that had a higher number of hydroxyl groups, especially those with ortho and para positions of the hydroxyl substitution.

S. macrophylla is a species native to Central and South America, and has been introduced and planted for its wood in many tropical countries such as Indonesia (Brown et al. 2003). In Indonesia, this wood has been highly prized in the production of furniture materials due its physical, mechanical, anatomical, and electrical properties (Husein et al. 2014, Anoop et al. 2014). In Jepara, Central Java, Indonesia, the utilization of $S$. macrophylla wood does not include bark, which is regarded as a waste. Previous work on antioxidant activity of the whole bark of this species has been initiated by Falah et al. (2008). However, there is no information of extractives and their antioxidant activity from both inner and outer bark of $S$. macrophylla. In this study, the bark of $S$. macrophylla was separated into inner and outer bark, then each part was analyzed for total phenolic content, total flavonoid content, and antioxidant activity.

\section{MATERIAL AND METHODS}

\section{Bark specimen}

The bark of $S$. macrophylla was collected from a furniture industry, SRIKANDIRATU in Jepara, Indonesia. The diameter of $\log$ wood was in arrange of $40 \mathrm{~cm}$ and the tree age was $>20$ years old. The bark sample was separated to inner and outer part with color of inner bark is light red and outer bark is dark red. The thickness of inner bark is $0.5-1 \mathrm{~mm}$ and outer bark is 1.5-3 mm. The bark sample was grinded to powder (60 - 80 mesh) before extraction.

\section{Extraction}

For the extraction, the sample of inner and outer bark (each $500 \mathrm{~g}$ ) was extracted with $n$-hexane and $\mathrm{MeOH}$ for $6 \mathrm{~h}$ and in hot water for $3 \mathrm{~h}$ in a reflux apparatus. The $\mathrm{MeOH}$ soluble extracts were then fractionated by ethyl acetate (EtOAc). The EtOAc fractionation was conducted by extracting $\mathrm{MeOH}$ soluble extracts with EtOAc for $12 \mathrm{~h}$ in room temperature using magnetic stirrer.

\section{Chemicals}

Gallic acid (97.5\%), quercetin ( $\geq 95 \%), \mathrm{DPPH}$, trimethylchlorosilane (TMCS) and N,O-bis(trimethylsilyl) acetamide (BSA) were purchased from Sigma-Aldrich (Germany) while phenol reagent (Folin-Ciocalteu), aluminium chloride, and sodium carbonate were purchased from Merck (Darmstadt, Germany). 


\section{Determination of total phenolic content (TPC)}

To observe TPC, $2.5 \mathrm{ml}$ of Folin-Ciocalteu reagent was mixed with $0.5 \mathrm{ml}$ of ethanol solution of the sample. The reaction was left to sit for $2 \mathrm{~min}$ before adding the sodium carbonate ( $2 \mathrm{ml}$ of $7.5 \%$ aqueous), then the solution was stood again for $30 \mathrm{~min}$. The absorbance of sample was read at $765 \mathrm{~nm}$ with an Ultaviolet (UV)/ Visible spectrophotometer (model SP-3000 Nano, Optima, Tokyo, Japan) and the results were expressed as gallic acid equivalents (mg GAE/g based on dry extract weight). The standard curve was made in concentration of 100, 50, 25, and 12.5 $\mu \mathrm{g} \cdot \mathrm{ml}^{-1}$ solutions of gallic acid in $\mathrm{MeOH}\left(\mathrm{y}=0.1097 \mathrm{x}-0.002 ; \mathrm{R}^{2}=0.9968\right)$. The Folin-Ciocalteu method used based on a previous study (Diouf et al. 2009). TPC were performed as the mean \pm standard deviation of three replications of measurement.

\section{Determination of total flavonoid content (TFC)}

The TFC assay was conducted as follows: to $2 \mathrm{ml}$ of sample $\left(1 \mathrm{mg} \cdot \mathrm{ml}^{-1}\right)$ was mixed with $2 \%$ of $\mathrm{AlCl}_{3} \cdot 6 \mathrm{H}_{2} \mathrm{O}$ solution $(2 \mathrm{~g}$ in $100 \mathrm{ml} \mathrm{MeOH})$. After $1 \mathrm{~h}$ incubation at $20^{\circ} \mathrm{C}$, the sample absorbance was read at $415 \mathrm{~nm}$ with an Ultraviolet (UV)/ Visible spectrophotometer (model SP-3000 Nano, Optima, Tokyo, Japan) and the results were expressed in quercetin equivalents (mg QE/g extract) (Brighente et al. 2007). The quercetin solutions in $\mathrm{MeOH}$ with concentration of $31.25,15.63,7.81$, and $3.91 \mu \mathrm{g} \cdot \mathrm{ml}^{-1}$ were made to perform the TFC calibration $(\mathrm{y}=0.0246 \mathrm{x}$ $\left.+0.0005 ; \mathrm{R}^{2}=0.9994\right)$. Each sample was conducted in three replications for TFC measurement.

\section{Gas chromatography mass spectrometry (GC-MS) analysis}

GC-mass spectrometry (GC-MS) data were collected with a GCMS-QP 2010 (Shimadzu, Japan). The $1 \mu \mathrm{l}$ of sylillated sample was injected to GC-MS machine. The GC condition: Rtx-5MS capillary column (30 m x $0.25 \mathrm{~mm}$ I.D. and $0.25 \mu \mathrm{m}$; GL Sciences, Tokyo, Japan); column temperature from $100^{\circ} \mathrm{C}(1 \mathrm{~min})$ to $320^{\circ} \mathrm{C}$ at $5{ }^{\circ} \mathrm{C} \cdot \mathrm{min}^{-1}$; injection temperature of $250^{\circ} \mathrm{C}$; detection temperature of $320^{\circ} \mathrm{C}$; acquisition mass range from of 50-800 amu using helium as the carrier gas. The mass spectrum of sample was compared to NIST library. The sylilation method was conducted by dissolving $2 \mathrm{mg}$ of sample into TMCS $(15 \mu \mathrm{l})$ and BSA (85 $\mu \mathrm{l})$ (Wijayanto et al. 2015). After $1 \mathrm{~h}$ incubation, the sample was evaporated and the dry extract was dissolved in $1 \mathrm{ml}$ of $\mathrm{MeOH}$. Peak relative method was used for quantification of individual substances.

\section{Determination of DPPH radicals scavenging activity}

Antioxidant activity assay was conducted according to a previous study (Baba and Malik, 2014). Briefly, $0.1 \mathrm{ml}$ extract in $\mathrm{MeOH}$ with different concentration (100-1000 ppm) was mixed and reacted with $3 \mathrm{ml}$ of $0.1 \mathrm{mM}$ DPPH. The reaction was left to sit for $30 \mathrm{~min}$ in a dark and chilled room, then the absorbance was read at $517 \mathrm{~nm}$. The antioxidant activity was calculated by Eq. 1 as follows:

DPPH scavenged $(\%)=100 \times($ Ao-A1) $/$ Ao

where: Ao is absorbance of blank, A1 is absorbance of sample.

The antioxidant value was also in units of $\mathrm{IC}_{50}$ (the concentration of sample that inhibits activity of 50\%).

\section{Statistical analysis}

The effects of bark part and extract fractions were calculated by analysis of variance (ANOVA). A Tukey's HSD (honestly significant difference) test was used to show which group means differ. All statistics were performed with SPSS 10.0 software 


\section{RESULTS AND DISCUSSION}

\section{Extractive content}

The inner and outer bark of $S$. macrophylla were extracted by $n$-hexane, $\mathrm{MeOH}$, and hot water, successively. The $\mathrm{n}$-hexane and $\mathrm{MeOH}$ extract of the inner bark were higher than that of the outer bark, but the hot water extract showed the opposite results (Arisandi et al. 2019a). In this study, the $\mathrm{MeOH}$ extracts from previous work were fractionated by EtOAc. In Fig. 1, the EtOAc soluble fraction of the inner and outer bark was at a lower level than EtOAc insoluble fraction. This indicates that the inner and outer bark of $S$. macrophylla have bigger insoluble polymers such as tannin. The presence of EtOAc insoluble fraction of inner and outer bark were $11.15 \%$ and $6.12 \%$, respectively. Those values were quite similar to $\mathrm{MeOH}$ extract of inner and outer bark (12.05\% and 6.27\%). These outputs encourage that the high concentration of insoluble polymers/tannins in the bark of $S$. macrophylla could increase the utilization of forest products in the future.

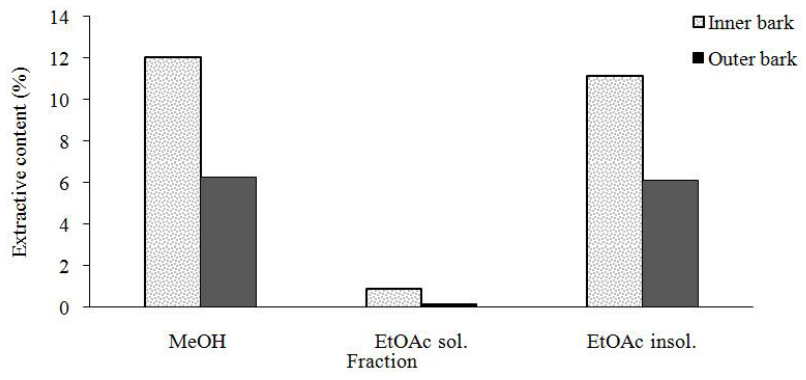

Fig. 1: Extractive content of S. macrophylla extraction; ethyl acetate soluble (EtOAc sol.) and ethyl acetate insoluble (EtOAc insol.)

\section{Phenol contents}

The results of TPC and TFC are shown in Fig. 2. ANOVA test showed significance in TPC and TFC in the interaction between bark and fraction (Tab. 1). The TPC values were significantly lower in the EtOAc soluble extract of inner bark. Meanwhile, insoluble fraction of both inner and outer bark showed significantly lower number of TFC compared to the soluble fractions. Furthermore, the soluble fraction of inner bark showed significantly higher values of TFC than outer bark.

Tab. 1: Two-way ANOVA for TPC and TFC value of S. macrophylla inner and outer bark.

\begin{tabular}{|l|c|c|c|}
\hline \multirow{2}{*}{ Source of variation } & \multirow{2}{*}{ df } & \multicolumn{2}{|c|}{ p value } \\
\cline { 3 - 4 } & & TPC & TFC \\
\hline Bark (B) & 1 & $<0.01^{* *}$ & $<0.01^{* *}$ \\
\hline Fraction (F) & 2 & $<0.01^{* *}$ & $<0.01^{* *}$ \\
\hline $\mathrm{B} \times \mathrm{F}$ & 2 & $0.03^{*}$ & $<0.01^{* *}$ \\
\hline Error & 12 & & \\
\hline Total & 18 & & \\
\hline
\end{tabular}

df: degrees of freedom;

at $5 \%$ level, n.s: not significant; *: $\mathrm{p}<0.05 ;{ }^{* *}: \mathrm{p}<0.01$. 

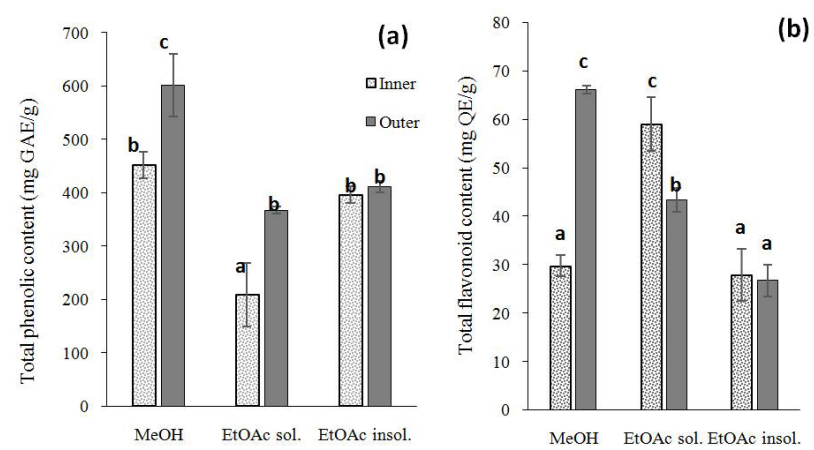

Fig. 2: The same letters are not statistically different at $p<0.05$ by Tukeytest. "after sentence of "TPC (a) and TFC (b) inner and outer bark of S. macrophylla; EtOAc insoluble and solublefractions.

Phenolic compounds are secondary metabolites commonly found in plant parts. These compounds were known to act as a defense mechanism of plants against pathogens and insects as they have generally effective bioactivities that may prove to be beneficial to the tree, such as insect deterrent (Wafula et al. 2013) and anti-fungal bioactivities (Zabka and Pavela 2013, Popa 2015). Previous research on Eucalyptus pellita bark also found a significantly higher total phenolic content in its bark compared to its sapwood, with similar range of 368.4 to $632.5 \mathrm{mg} \mathrm{GAE} / \mathrm{g}$ (Arisandi et al. 2019b). Thus, this higher amount of TPC in the outer bark might be explained as a defense mechanism of the tree. Moreover, the higher amount of TPC in the EtOAc insoluble extract indicates that the phenolic content of $S$. macrophylla bark is dominated by phenols with heavier molecular weight such as tannins. Previous research by Waheed et al. (2014) showed a higher amount of low molecular weight compounds of flavonoid and terpenoid groups in the EtOAc fraction of Ballota limbata extract. In TFC, the $\mathrm{MeOH}$ extract of outer bark showed a higher level than inner bark. On the contrary, TFC of the inner bark of EtOAc soluble and insoluble extract showed a higher concentration than outer bark extract.

\section{GC-MS analysis}

The GC-MS results in the bark of S. macrophylla showed that phenolics, fatty acids, and alcohols were abundant (Tab. 2). In the inner bark, the constituent mainly consisted of fatty acid $(87.12 \%)$ i.e. pentadecanoic acid $(29.78 \%)$. In the outer bark the constituent was dominated by phenolic compounds, such as catechol (58.04\%), while in inner bark, resorcinol was the dominating phenolic compound (8.45\%). The chromatogram of sample is displayed in Fig. 3.

Tab. 2: Constituents of EtOAc soluble extracts of S. macrophylla inner and outer bark.

\begin{tabular}{|c|c|l|c|c|c|}
\hline \multirow{2}{*}{ Number } & Ret. time & \multicolumn{1}{|c|}{ Constituents } & \multicolumn{2}{|c|}{ Sample (\% of dried extract) } & Similarity \\
\cline { 3 - 6 } & $(\mathbf{m i n})$ & & Inner bark & Outer bark & index (\%) \\
\hline & & Phenolics & 12.17 & 82.65 & \\
\hline 1 & 10.4 & Catechol & $\operatorname{tr}$ & 58.04 & 96 \\
\hline 2 & 11.4 & Benzoic acid & $\operatorname{tr}$ & 11.08 & 55 \\
\hline 3 & 12.5 & Resorcinol & 8.45 & 2.79 & 94 \\
\hline 4 & 13.9 & 4-Methylcatechol & $\operatorname{tr}$ & 3.07 & 81 \\
\hline 5 & 15.4 & Syringol & $\operatorname{tr}$ & 6.56 & 87 \\
\hline
\end{tabular}




\begin{tabular}{|c|c|l|c|c|c|}
\hline 6 & 21.9 & Antiarol & 1.16 & $\operatorname{tr}$ & 81 \\
\hline 7 & 23.9 & 4-Hydroxybenzyl alcohol & $\mathrm{nd}$ & 1.11 & 55 \\
\hline 8 & 25.9 & Syringic acid & 1.72 & $\operatorname{tr}$ & 87 \\
\hline 9 & 30.4 & 2,3,4-Trimethoxycinnamic acid & 0.84 & $\operatorname{tr}$ & 63 \\
\hline & & Fatty acids and alcohols & 87.12 & 8.43 & \\
\hline 10 & 24.6 & Myristic acid & 0.77 & $\mathrm{nd}$ & 84 \\
\hline 11 & 27.4 & Palmitic acid, methyl ester & 4.63 & 1.03 & 97 \\
\hline 12 & 28.2 & Pentadecanoic acid & 29.78 & 7.4 & 94 \\
\hline 13 & 28.6 & 10-Methyleicosane & 0.89 & $\mathrm{nd}$ & 75 \\
\hline 14 & 30.2 & Linolelaidic acid, methyl ester & 4.65 & $\mathrm{nd}$ & 96 \\
\hline 15 & 30.3 & 9-Octadecenoic acid, methyl ester & 2.95 & $\mathrm{nd}$ & 93 \\
\hline 16 & 30.7 & Methyl stearate & 0.74 & $\mathrm{nd}$ & 87 \\
\hline 17 & 31.0 & 11,14-Eicosadienoic acid, methyl ester & 21.2 & $\mathrm{nd}$ & 88 \\
\hline 18 & 31.2 & cis-Vaccenic acid & 18.01 & $\mathrm{tr}$ & 92 \\
\hline 19 & 31.3 & Stearic acid & 3.5 & $\mathrm{nd}$ & 92 \\
\hline
\end{tabular}

Note: (nd): not detected; (tr): trace.

Catechol (Fig. 4b) was detected as the major compound in the bark of $S$. macrophylla. The high concentration of catechol in the outer bark of $S$. macrophylla indicated that the presence of tannin with a catechol monomer. A previous work (Falah et al. 2008) isolated flavanols i.e., Swietema crophyllanin, catechin, and epicatechin from the bark of $S$. macrophylla. The chemical structure of catechin and epicatechin commonly have a catechol structure in their B ring (Fig. 5a).

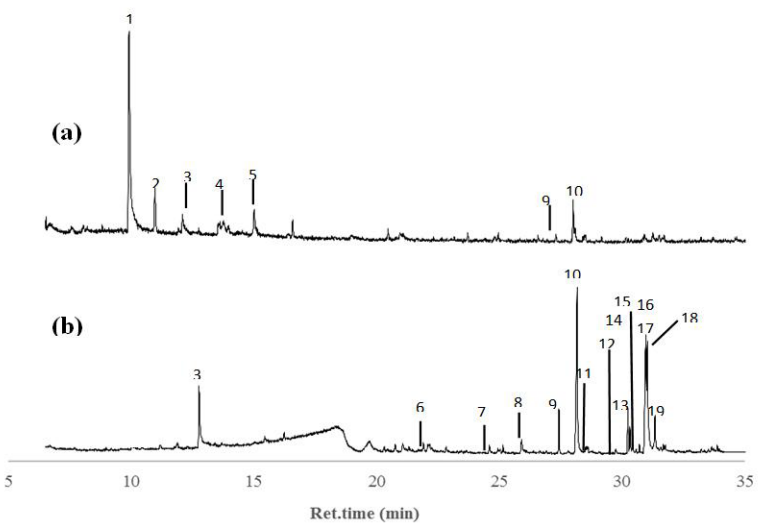

Fig. 3: Chromatogram GC-MS of outer (a) and inner (b) bark of EtOAc soluble extracts from $S$. macrophylla: 1. Catechol, 2. Benzoic acid, 3. Resorcinol, 4. 4-Methylcatechol, 5. Syringol, 6. Antiarol, 7. 4-Hydroxybenzyl alcohol, 8. Syringic acid, 9. 2,3,4-Trimethoxycinnamic acid, 10. Myristic acid, 11. Palmitic acid, methyl ester, 12. Pentadecanoic acid, 13. 10-Methyleicosane, 14. Linolelaidic acid, methyl ester, 15. 9-Octadecenoic acid, methyl ester, 16. Methyl stearate, 17. 11,14-Eicosadienoic acid, methyl ester, 18. cis-Vaccenic acid, and 19. Stearic acid.

In part of the inner bark, Tab. 2 and Fig. 3 show that fatty acids and alcohols dominated the composition of extractives. It has been suggested that this part has a role in nutrient transfer 
and also as storage to save energy, such as sugars and fatty acids. This result is in agreement with previous studies (Morris et al. 2016, Masendra et al. 2018). In the case of phenolic compounds, the resorcinol in the inner bark part dominated the extractive constituents. In the structure of flavanols, the A ring has the structure of resorcinol (Fig. 5a). Thus, this fact also supports the presence of catechin or epicatechin as tannin monomers in the bark of S. macrophylla. The higher presence of resorcinol also suggests that the bark of S. macrophylla can be considered as a good source of resorcinol and catechol. This was in agreement with previous studies in the bark of Pinus radiata (Case et al. 2014, Pinto et al. 2018). The high concentration of resorcinol and catechol could possibly lead to the development of $S$. macrophylla bark for adhesives, pharmaceuticals, and leather industries.

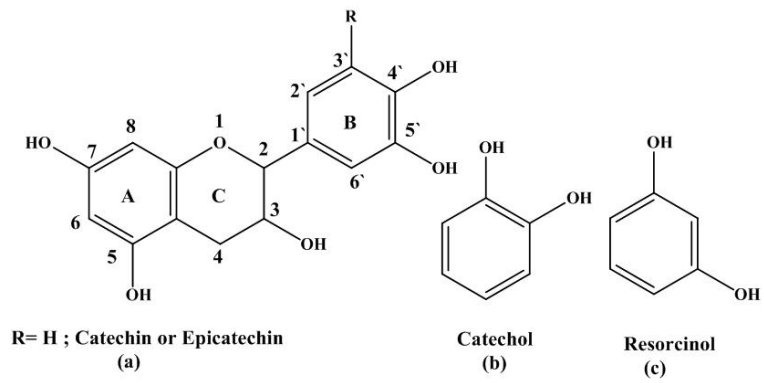

Fig. 4: Chemical structure of flavanols and their precursors.

\section{Antioxidant activity}

The results of antioxidant activity by $\mathrm{IC}_{50}$ of the bark are shown in Fig. 5. The results were compared with the crude $\mathrm{MeOH}$ extract antioxidant activity. The crude $\mathrm{MeOH}$ extract showed that outer bark had a higher antioxidant activity (a lower $\mathrm{IC}_{50}$ value) compared to inner bark. Furthermore, after fractionation, the soluble fraction of EtOAc of outer bark also showed the same pattern where levels of antioxidant activity were higher than inner bark. In the case of EtOAc insoluble, the result was different. The inner bark part showed a higher level of antioxidant properties. In this study, the ANOVA of the antioxidant activity showed a significant difference (Tab. 3).

Tab. 3: Two-way ANOVA for $I C_{50}$ value of $S$. macrophylla inner and outer bark.

\begin{tabular}{|c|c|c|}
\hline Source of variation & df & p value of DPPH IC $_{\mathbf{5 0}}$ \\
\hline Bark (B) & 1 & $0.03^{*}$ \\
\hline Fraction (F) & 2 & $0.02^{*}$ \\
\hline B $\times$ F & 2 & $<0.01^{* *}$ \\
\hline Error & 12 & \\
\hline Total & 18 & \\
\hline
\end{tabular}

df: degrees of freedom; at $5 \%$ level, n.s: not significant; ${ }^{*} \mathrm{p}<0.05 ;{ }^{* *} \mathrm{p}<0.01$.

Results showed that the antioxidant activity of the inner bark extract is mainly caused by the EtOAc insoluble fraction's compound. Furthermore, although without significant difference between values, the crude extract of the outer bark part showed stronger antioxidant activity than the fractionated parts. Synergism between natural compounds can be defined as an increased 
effect, such as antioxidant activity, with the combination of those compounds Sonam and Guleria (2017). This synergism might explain why the crude extract of the outer bark showed a stronger activity. The finding of higher antioxidant activity levels in outer bark than in inner bark corroborates the ecological role of outer bark in protecting of the living tissue from damages or microorganisms attack (Wafula et al. 2013, Zabka and Pavela 2013, Popa 2015). In the opposite, the lower antioxidant activity in the crude extract of the inner bark part may be caused by the antagonistic effect between EtOAc soluble and insoluble fractions. A comparison with the standard of gallic acid and quercetin exhibited that the antioxidant in the samples were still at lower levels (Fig. 5).

The EtOAc soluble fraction of outer bark exhibited high levels of antioxidant activity (Fig. 5). This antioxidant activity might be caused by the high concentration of catechol. Catechol is a simple structured phenolic compound with two hydroxyl groups in an ortho position. Previous structure to activity relationship study has found better antioxidant activity from catechol compared to other simple phenols and anilines. Catechols have been shown as able to neutralize two peroxyl radicals (Valgimigli et al. 2008, Bendary et al. 2013). The ortho position of its hydroxyl groups was suspected as the reason for its effectivity in neutralizing DPPH radicals, where the lower bond dissociation energy makes it easier for catechol to lose its $\mathrm{H}$ atom. On the other hand, phenols with a meta position of hydroxyl group, such as resorcinol, showed a lower antioxidant activity (Bendary et al. 2013). In addition, catechol is known to be a degradation product of flavonoid compounds. Through bacterial degradation, catechin can be degraded into phloroglucinol carboxyl acid, protocatechuic acid, and catechol (Vasundevan and Mahadevan 1990, Arunachalam et al. 2003).

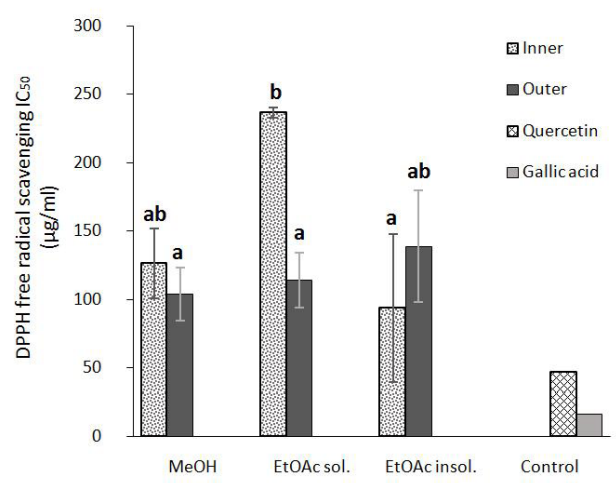

Fig. 5: Antioxidant activity of inner and outer bark S. macrophylla; MeOH crude, EtOAc insoluble, and EtOAc soluble fractions.

In the EtOAc soluble fraction of inner bark, the antioxidant levels were lower compared to other extracts. This may be due to the lower presence of phenolic compounds than fatty acids and alcohols. Additionally, the phenolic compound of resorcinol that dominated in this bark part may be less effective at inhibiting DPPH than catechol which was in a higher level in outer bark. However, as the catechol and resorcinol precursors were detected in the bark sample, this also suggests that the bark contains catechin or epicatechin as tannin monomers. Thus, it is reasonable that antioxidant levels of EtOAc insoluble fraction from inner bark was higher than other fractions. 


\section{Phenol contents and antioxidants activity correlation}

Correlations between TPC, TFC, and antioxidant activity have been plotted in Figs. 6 and 7. The results showed positive correlations between TPC and DPPH scavenging activity in Fig. $6 \mathrm{a}\left(\mathrm{R}^{2}=0.6\right.$ and 0.7$)$. Furthermore, a specific correlation was found in inner and outer barks as the TPC of inner bark and DPPH showed strong correlations in Fig. $6 \mathrm{~b}\left(\mathrm{R}^{2}=0.94\right.$ and 0.98). A low degree of correlation was measured in TPC of outer bark and DPPH in Fig. 6c $\left(\mathrm{R}^{2}=0.1\right.$ and 0.05$)$.

In general, a sample with a high level of TPC gave a high level of DPPH. The correlation between total phenolic content and DPPH scavenging activity such in Fig. $6 \mathrm{a}$ and $6 \mathrm{~b}$ was also found in previous works on Punica granatum, blackberries, Thymus vulgaris, and Hyoscyamus gaagheri (Eddebbagh et al. 2016, Guedes et al. 2017, Amamra et al. 2018, Hossain et al. 2019). Phenolic compounds are classified as its own group due to its benzene ring with hydroxyl group attached to it. Hydroxyl group in phenolic compounds is a good hydrogen donor, which can react and neutralize reactive oxygen such as DPPH (Pereira et al. 2009, Miguel-Chávez 2017). Thus, high concentration of phenolic compounds in an extract is often followed by a high antioxidant activity. In addition, the outer bark sample showed higher levels of TPC and catechol than inner bark. A significant correlation could not be found by analysis regression (Fig. 6c). This result was similar to a previous work on 13 citrus species peels and tissues (Ghasemi et al. 2009).

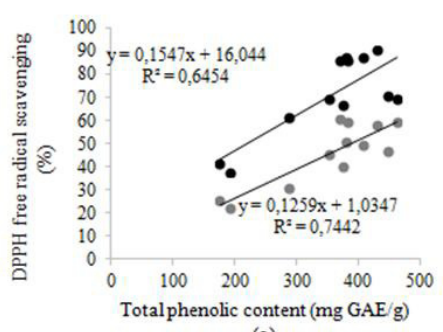

(a)

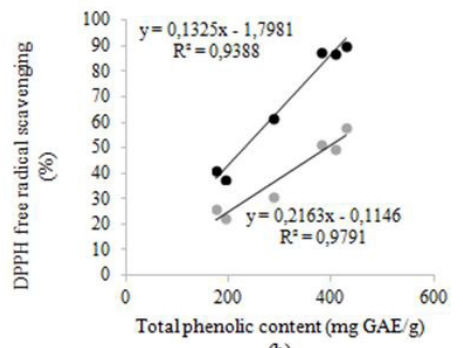

(b)

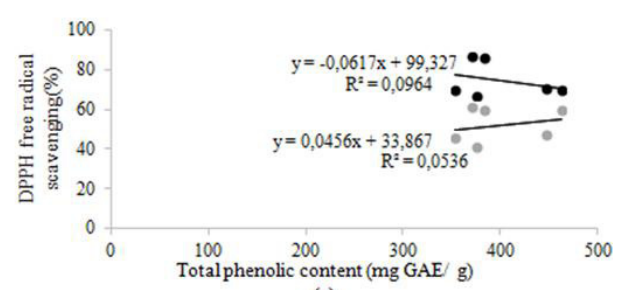

(c)

Fig. 6: Correlation between TPC and DPPH free radical scavenging activity in both outer and inner bark (a), inner bark only (b), and outer bark only (c); gray circle in $100 \mu \mathrm{g} \cdot \mathrm{ml}^{-1}$ and black circle in $200 \mu \mathrm{g} \cdot \mathrm{ml} \mathrm{l}^{-1}$ concentration.

The correlation also was observed between TFC and DPPH scavenging activity (Fig. 7). All correlations showed weak and negative relationships. In Fig. 7a, a negative correlation was demonstrated with $\mathrm{R}^{2}=0.3$ and 0.4 . This suggests that TFC in the sample did not correspond with the DPPH levels. A strong negative correlation was calculated between TFC of inner 
bark and DPPH $\left(\mathrm{R}^{2}=0.6\right.$ and 0.7$)$. This indicates that the flavonoid constituents in the inner bark sample do not relate to DPPH scavenging activity values. This could be due to the high concentration of fatty acids and alcohols and lower phenolic compounds in the inner bark part. In Fig. 7c, the TFC of the outer bark part was described. In $200 \mu \mathrm{g} \cdot \mathrm{ml}^{-1}$ concentration of sample, the correlation was still negative even in low $\mathrm{R}^{2}(0.1)$, while in $100 \mu \mathrm{g} \cdot \mathrm{ml}^{-1}$ with low $\mathrm{R}^{2}(0.05)$ value but the correlation was positive. In Fig. 7c, generally the sample with a high level of TFC also had a high level of DPPH radical scavenging activity, but it could not be explained with the correlation. These results agree with a previous study by Ghasemi et al. (2009) on 13 citrus species peels and tissues.

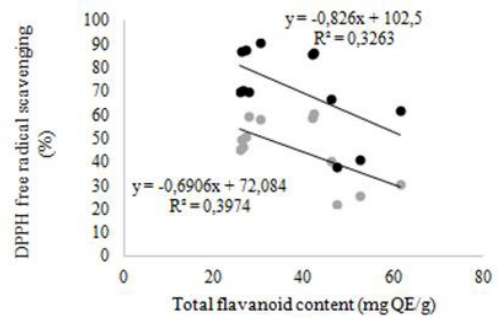

(a)

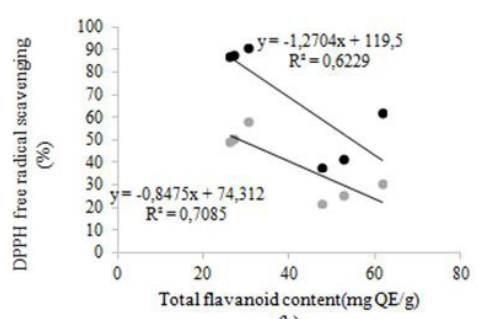

(b)

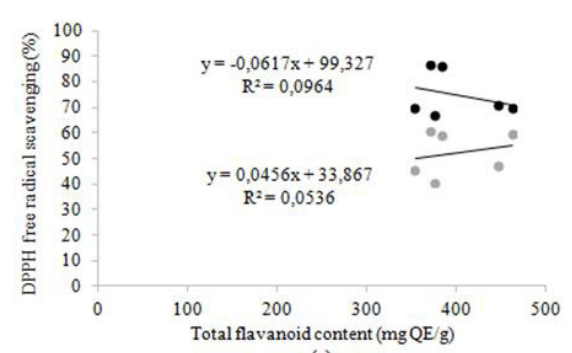

(c)

Fig. 7: Correlation between TFC and DPPH free radical scavenging activity correlation in both outer and inner bark (a), inner bark only (b), and outer bark only (c); gray circle in $100 \mu \mathrm{g} / \mathrm{ml}$ and black circle in $200 \mu \mathrm{g} / \mathrm{ml}$ concentration.

\section{CONCLUSIONS}

The phenol contents and antioxidant activity of $\mathrm{MeOH}$ soluble extract of $S$. macrophylla bark have been observed. The $\mathrm{MeOH}$ and EtOAc soluble extracts of outer bark showed higher antioxidant activity than the inner bark. The TPC measurement showed that outer bark had higher levels than inner bark. These findings suggest that the outer bark of S. macrophylla ecologically work as a protector of living tissues and natural antioxidant sources. With regard to $\mathrm{TFC}$, only the $\mathrm{MeOH}$ crude extract showed higher values in the outer bark rather than the inner bark. The high antioxidant activity level was linearly related with GC-MS detection of phenolic compounds i.e. catechol and resorcinol in inner and outer bark sample. Correlation between phenol contents and antioxidant activity suggests that TPC strongly relates to antioxidant activity in the bark of $S$. macrophylla. 


\section{ACKNOWLEDGMENTS}

We thank to SRIKANDIRATU, an industry of furniture in Jepara, Indonesia for the bark of S. macrophylla.

\section{REFERENCES}

1. Amamra, S., Cartea, M.E., Belhaddad, O.E., Soengas, P., Baghiani, A., Kaabi, I., Arrar L., 2018: Determination of total phenolics contents, antioxidant capacity of Thymus vulgaris extracts using electrochemical and spectrophotometric methods. International Journal of Electrochemical Science 13(8): 7882-7893.

2. Anoop, E.V., Jijeesh, C.M., Sindhumathi, C.R., Jayasree C.E., 2014: Wood physical, anatomical and mechanical properties of big leaf mahogany (Swietenia macrophylla Roxb) a potential exotic for South India. Research Journal of Agriculture and Forestry Sciences 2(8): 7-13.

3. Arisandi, R., Masendra, Purba, B.A.V., Wati, F.Z., Ihda, F.V., Sumantri, F., Lukmandaru, G., 2019: Lipophilic extractives of Mahogany (Swietenia macrophylla King) barks. Proceeding of $9^{\text {th }}$ International Symposium of Indonesian Wood Research Society, Pp 92-102.

4. Arisandi, R., Marsoem, S.R., Lukmandaru, G., 2019: The contents of phenolics and cell wall component of Eucalyptus pellita F. Muell stemwood and bark. Wood Research 64(3): 411-422.

5. Arunachalam, M., Mohan, R.M., Mohanc, N., Mahadevand, A., 2003: Biodegradation of catechin. Proceedings of the Indian National Science Academy 69(4): 353-370.

6. Baba, S.A., Malik, S.A., 2015: Determination of total phenolic and flavonoid content, antimicrobial and antioxidant activity of a root extract of Arisaema jacquemontii Blume. Journal of Taibah University for Science 9(4): 449-454.

7. Bendary, E., Francis, R.R., Ali, H.M.G., Sarwat, M.I., El-Hady, S., 2013: Antioxidant and structure-activity relationships (SARs) of some phenolic and anilines compounds. Annals of Agricultural Science 58(2): 173-181.

8. Brighente, I.M.C., Dias, M., Verdi, L.G., Pizzolatti, M.G., 2007: Antioxidant activity and total phenolic content of some brazilian species. Pharmaceutical Biology 45(2): 156-61.

9. Brown, N., Jennings, S., Clements, T., 2003: The ecology, silviculture and biogeography of mahogany (Swietenia macrophylla): a critical review of evidence. Plant Ecology and Evolution System 6(1): 37-49.

10. Case, P.A., Bizama, C., Segur, C., Wheeler, M.C., Berg,A., DeSisto, W.J., 2014: Pyrolysis of pre-treated tannins obtained from radiata pine bark. Journal of Analytical and Applied Pyrolysis 107: 250-255.

11. Cory, H., Passarelli, S., Szeto, J., Tamez, M., Mattei, J., 2018: The role of polyphenols in human health and food systems: a mini-review. Frontiers in Nutrition 5(87): 1-9.

12. Diouf, P.N., Stevanovic, T., Cloutier, A., 2009: Antioxidant properties and polyphenol contents of trembling aspen bark extracts. Wood Science and Technology 43(5): 457-470.

13. Eddebbagh, M., Messaoudi, M., Abourriche, A., Berrada, M., Attaleb, M., Benbacer, L., Bennamara, A., 2016: Correlation of the cytotoxic and antioxidant activities of moroccan pomegranate (Punica granatum) with phenolic and flavonoid contents. Journal of Pharmacy and Pharmacology 68(4): 511-19. 
14. Elansary, H.O., Szopa, A., Kubica, P., Ekiert, H., Mattar, M.A., A1-Yafrasi, M.A., El-Ansary, D.O., El-Abedin, T.K.Z., Yessoufou, K., 2019: Polyphenol profile and pharmaceutical potential of Quercus spp. bark extracts. Plants 8(11): 486.

15. Falah, S., Suzuki, T., Katayama, T., 2008: Chemical constituent from Swietenia macrophylla bark and their antioxidant activity. Pakistan Journal of Biological Sciences 11(16): 2007-2012.

16. Ghasemi, K., Ghasemi, Y., Ebrahimzadeh, M.A., 2009: Antioxidant activity, phenol and flavanoid contents of 13 citrus species peels and tissues. Pakistan Journal of Pharmaceutical Sciences 22(3): 277- 281.

17. Guedes, M.N.S., Pio, R., Maro, L.A.C., Lage, F.F., Abreu, M.P.D.A., Saczk, A.A., 2017: Antioxidant activity and total phenol content of blackberries cultivated in a highland tropical climate. Acta Scientiarum 39(1): 43- 48.

18. Halliwell, B., Gutteridge, J.N.C., 1999: Mechanism of damage of cellular targets by oxidative stress: lipid peroxidation. In: Free radicals in biology and medicine (ed. Halliwell B, Gutteridge JMC). Oxford University Press. Oxford, Pp. 284-313.

19. Hossain, M.A., Weli, A.M., Ahmed, S.H.J., 2019: Comparison of total phenols, flavonoids and antioxidant activity of various crude extracts of Hyoscyamus gaagheri traditionally used for treatment of epilepsy. Clinical Phytoscience 5(20): 1- 8.

20. Husein, I., Sadiyo, S., Nugroho, N., Wahyudi, I., Agustina, A., Komariah, R.N., Khabibi, J., Purba, C.Y.K., Ali, D., Iftor, M., Kahar,T.P., Wijayanto, A., Jamilah, M., 2014: Electrical properties of Indonesian hardwood, case study: Acacia mangium, Swietenia macrophylla and Maesopsis eminii. Wood Research 59(4): 695- 704.

21. Iravani, S., Zolfaghari, B., 2011: Pharmaceutical and nutraceutica effects of Pinus pinaster bark extract. Research in Pharmaceutical Sciences 6(1):1-11.

22. Masendra, Ashitani, T., Takahashi, K., Lukmandaru, G., 2018: Lipophilic extractives of the inner and outer barks from six different Pinus species grown in Indonesia. Journal of Forestry Research 29(5): 1329-36.

23. Miguel-Chávez, R.S., 2017: Phenolic antioxidant capacity: a review of the state of the art. In: Phenolic Compounds - Biological Activity (ed. Soto-Hernandez M, Palma-Tenango M, and Garcia-Mateos MR). IntechOpen, London, Pp 59-74.

24. Morris, H., Brodersen, C., Schwarze, F.W.M.R., Jansen S., 2016: The parenchyma of secondary xylem and its critical role in tree defense against fungal decay in relation to the CODIT model. Frontiers in Plant Science 7(1665): 1-18.

25. Ogawa, S., Yazaki, Y., 2018: Tannins from Acacia mearnsii De Wild. bark: tannin determination and biological activities. Molecules 23(4).

26. Pereira, D.M., Valentão, P., Pereira, J.A., Andrade, P.B., 2009: Phenolics: from chemistry to biology. Molecules 14(6): 2202-2211.

27. Pérez-Jiménez, J., Neveu, V., Vos, F., Scalber, A., 2010: Identification of the 100 richest dietary sources of polyphenols: an application of the phenol-explorer database. European Journal of Clinical Nutrition 64: 112-20.

28. Pinto, P., Romero, R., Carrie, M., Apelt, J., Segura, C., 2018: Fast pyrolysis of tannins from pine bark as a renewable sources of catechols. Journal of Analytical and Applied Pyrolysis 136: 69- 76.

29. Popa, V.I., 2015: Wood bark as valuable raw material for compounds with biological activity. Celuloză şi Hârtie 64(4): 1-14.

30. Rees, A., Dodd, G.F., Spencer, J., 2018: The effects of flavonoids on cardiovascular health: a review of human intervention trials and implications for cerebrovascular function. Nutrients 10(12): 1852. 
31. Rosell, J.A., Gleason, S., Méndez-Alonzo, R., Chang, Y., Westoby, M., 2014: Bark functional ecology: evidence for tradeoffs, functional coordination, and environment producing bark diversity. New Phytologist 201(2): 486-497.

32. Singh, A., Holvoet, S., Mercenier, A., 2011: Dietary polyphenols in the prevention and treatment of allergic diseases. Clinical \& Experimental Allergy 41(10): 1346-1359.

33. Sonam, K.S., Guleria, S., 2017: Synergistic antioxidant activity of natural products. Annals of Pharmacology and Pharmaceutics 2(8): 1-6.

34. Sroka, Z., Cisowski, W., 2003: Hydrogen peroxide scavenging, antioxidant, and antiradical activity of some phenolic acids. Food and Chemical Toxicology 41: 753-758.

35. Valgimigli, L., Amorati, R., Fumo, M.G., Dilabio, G.A., Pedulli, G.F., Ingold, K.U., Pratt, D.A., 2008: The unusual reaction of semiquinone radicals with molecular oxygen. The Journal of Organic Chemistry 73(5): 1830-41.

36. Vasundevan, N., Mahadevan, A., 1990: Utilization of catechin by microorganism. Current Science 59(24): 1323-25.

37. Wafula, M.P, Hassanali, A., Swaleh, S., 2013: Phenolic and monoterpenoid mosquito repellent constituents of headspace vapors of Conyza newii. Journal of the Kenya Chemical Society 7(1): 7-10.

38. Waheed, I., Ahmad, M., Syed, N.H., Ashraf, R., 2014: Investigation of phytochemical and antioxidant properties of methanol extract and fractions of Ballota limbata (Lamiaceae). Indian Journal of Pharmaceutical Sciences 76(3): 251-256.

39. Wang, S., Moustaid-Moussa, N., Chen, L., Mo, H., Shastri, A., Su, R., 2014: Novel insights of dietary polyphenols and obesity. Journal of Nutritional Biochemistry 25(1): 1-18.

40. Wijayanto, A., Dumacay, S., Gerardin-Charbonnier, C., Sari, R.K., Syafii, W., Gerardin, P., 2015: Phenolic and lipophilic extractives in Pinus merkusii jungh. et de Vries knots and stemwood. Industrial Crops and Products 69: 466-471.

41. Zabka, M., Pavela, R., 2013: Antifungal efficacy of some natural phenolic compounds against significant pathogenic and toxinogenic filamentous fungi. Chemosphere 93(6): 1051-6.

\author{
Masendra, Brandon Aristo Verick Purba, Ganis Lukmandaru* \\ Universitas Gadjah Mada \\ FACULTY OF ForESTRY \\ Department of Forest Products Technology \\ Jl. Agro No. i, Bulaksumur \\ 5528I Yogyakarta \\ INDONESIA
}

*Corresponding author: glukmandaru@ugm.ac.id 
